\title{
飛行と気象の状況による予測飛行時間の不確かさのモデル化*1 Feasibility Study on Modeling of Flight Time Prediction Uncertainty using Flight and Meteorological Conditions
}

\author{
元 谷 章 博*3 ·武 市昇 $* 2, * 3$
}

Akihiro Motodani and Noboru TAKEICHI

Key Words : Air Traffic Management, 4 Dimensional Trajectory, Flight Time Uncertainty, Prediction Model

\begin{abstract}
A precise flight time uncertainty prediction is expected to enable a more efficient air traffic management. According to an uncertainty propagation equation derived from a physical model, the flight time uncertainty increases as a function of ground speed and the variances of true air speed and head wind speed. These factors also depend on the flight and meteorological conditions. It is expected possible to improve the uncertainty prediction accuracy by appropriately taking these factors into its modeling. Through the clustering analysis of the actual flight and weather forecast data, the feasibility of the flight time uncertainty modeling using the flight speed and weather forecast information is clearly demonstrated.
\end{abstract}

\section{1. は じめ に}

世界的な経済成長や国際化により航空交通需要の増加が 予測されている1). この需要増加に対応すべく航空交通管 理システムの抜本的な変勒計画されており, その一つに 現行の空域ベース運用から軌道ベース運用への移行が挙げ られる。この軌道ベース運用では, 離着陸を含むすべての 飛行を一元的に管理することが計画されており2), 各航空 機は予め設定された軌道に沿って飛行する。このため軌道 ベース運用の実現に向け, 航空機の正確な時間管理が重要 となり, 四次元航法が注目されている. 四次元航法は, 精密 な時間管理のために，通過地点とその通過時刻により指定 した経路による運航管理方法である3). しかし, 飛行中の航 空機は, 気象などの影響を受けるため, 予測飛行時間に誤 差が生じることは避けられない.この予測飛行時間の誤差 の程度，つまり予測飛行時間の不確かさを予測し管理に導 入することで，より効率的な運用が可能になるものと考え られる。一例として, 航空機間の時間間隔を安全性を保証 しながら最適に設定することで空域容量の拡大を図ること が挙げられる ${ }^{4}$. このような効率的な運航を目指して, 予測 飛行時間の不確かさの予測やモデル化に関する研究が行わ れてきた。その中で, 飛行時間の予測誤差の標準偏差が飛 行距離あるいは時間に比例することが理論的に示され4,5), さらに複数の研究において, 特定の期間（数日〜数年）の

*1 (C) 2018 日本航空宇宙学会

平成 29 年 4 月 14 日, 日本航空宇宙学会第 48 期年会講演会にて 発表

平成 29 年 8 月 2 日原稿受付

*2 連絡先著者 (Corresponding author): takeichi@tmu.ac.jp

*3 首都大学東京システムデザイン研究科航空宇宙システム工学域
特定の経路の航空機の飛行時間を解析し，飛行時間の予測 誤差の標準偏差が飛行距離あるいは時間に比例することが 実証されている6 8). このように過去の研究では, 予測飛行 時間の不確かさと飛行距離や時間との比例関係のみを示す 単純なモデルが得られているのみである.

本来，予測飛行時間の不確かさは，様々な要因の影響に より生じると考えられるため，その様々な誤差要因と影響 を明らかにし，それを考慮した予測飛行時間の不確かさを 予測する詳細なモデルが望まれる。そこで筆者らは，巡航 直線飛行における予測飛行時間の誤差伝搬モデルを構築し, 様々なパラメータのうち, まず飛行速度の影響を明らかに した9)。本研究では, 飛行速度だけでなく気象予報情報を 用いた予測飛行時間の不確かさの予測の可能性を明らかに する。このため, 運航デー夕および気象予報デー夕に対し てクラスタリングを適用し, 不確かさの予測における飛行 状況と気象状況の影響を明らかにする.

\section{2. データの処理}

2.1 使用するデータ 本研究では, SSR Mode S シス テムにより取得した運航データを使用する. SSR Mode S システムが提供するデータ内容には，レーダー測位による 緯度・経度の位置情報に加え, 指示大気速度, 真大気速度, マッハ数, 対地速度, 気圧高度などの航空機からダウンリ ンクされた動態情報が含まれる10). 2015 年 8, 9 月のデー 夕を使用する. また, 数值気象予報值として気象庁が提供 する全球モデル数值予報值 GSM ${ }^{11)}$ を使用する. GSM の 予報值は 6 時間ごとに更新され，最も予測精度がよいと考 えられる各予報時刻における初期予報值を緯度・経度・高 度・時刻に対して線形補間し，任意の時刻・位置の気象予 
報值を得る，本研究では，風速と気温を使用する.

2.2 目標飛行時間の推定 本研究では, 予測飛行時間 の不確かさを定量的に評価するために飛行時間の予測誤差 の標準偏差を指標とする. 飛行時間の予測誤差は, 目標飛 行時間と実際の飛行時間の差で求めることができるが，前 節で述べた SSR Mode S システムによる運航データから は各航空機の目標飛行時間を直接得ることができない. そ こで，数值気象予報值 GSM を用いて各航空機が目標とし た飛行時間を推定することとした。

目標飛行時間という各航空機の飛行意図を推定するにあ たり，まず明確な飛行意図をもっているとみなせる飛行区 間を抽出する。巡行区間における航空機は, 指示大気速度, 真航路角, 気圧高度を保って飛行することが多いため, 各 飛行軌道の指示大気速度の最頻值から $\pm 5[\mathrm{kt}]$ 以内加真 航路角の最頻值から $\pm 1.5[\mathrm{deg}]$ 以内を $100 \mathrm{~km}$ 以上維持し ながら巡航している等速・直線・巡航区間を, 明確な飛行 意図をもつ飛行区間として抽出する。ただし, 各飛行軌道 の気圧高度の最頻值から $\pm 100[\mathrm{ft}]$ の区間を巡行区間とみ なす. 抽出された飛行軌道デー夕数は 13604 となった. 抽 出された飛行軌道を第 1 図に示す.

次に，抽出後の各飛行の目標飛行時間 $T$ を推定する. あ る距離 $D$ を飛行するときの目標飛行時間 $T$ を推定するこ とは, 目標対地速度 $V_{G S}$ を推定することと等価である（式 (1)). そこで, 意図したとみなせる指示大気速度から数值 気象予報值を用いて算出する対地速度を目標対地速度と想 定する. 式 (2)により, 指示大気速度 $V_{I A S}$ を機首方向の真 対気速度 $V_{T A S}{ }^{\prime}$ に変換する。 ただ, $p$ は気圧高度より標 準大気モデルから求めた気圧， $\rho$ は気温から求めた大気密 度である。これを式 $(3)$ により真航路方向に変換した值を 目標真対気速度 $V_{T A S}$ とみなす。.ただし， $\theta_{W}$ は航空機の 機首方向と真航路方向の差である.

$T=\frac{D}{V_{G S}}$

$V_{T A S^{\prime}}$

$$
=\left[\frac{2}{\mu} \frac{p}{\rho}\left\{\left(1+\frac{p_{0}}{p}\left[\left(1+\frac{\mu}{2} \frac{\rho_{0}}{p_{0}} V_{I A S^{2}}\right)^{\frac{1}{\mu}}-1\right]\right)^{\mu}-1\right\}\right]^{\frac{1}{2}}
$$

$V_{T A S}=V_{T A S^{\prime}} \cos \theta_{W}$

この目標真対気速度 $V_{T A S}$ と真航路方向の風速 $W_{H}$ の予報 值の和から目標対地速度 $V_{G S}\left(=V_{T A S}+W_{H}\right)$ が求まり, ある距離 $D$ を飛行したときの目標飛行時間 $T$ を推定する ことができる. 明確な飛行意図をもつとみなした抽出デー 夕（第 1 図）の対地速度の観測值から求めた $10 \mathrm{~km}$ の飛行 時間と推定した目標飛行時間の誤差の分布を第 2 図に示す.

2.3 類似する飛行データのクラスタリング 予測飛行 時間の不確かさを飛行と気象の状況ごとに評価するために, 抽出後の飛行デー夕を類似する飛行データごとに分類する. このように，データの全集合から類似する特徵パラメータ をもつデータ集合に分類する手法をクラスタリングといい,

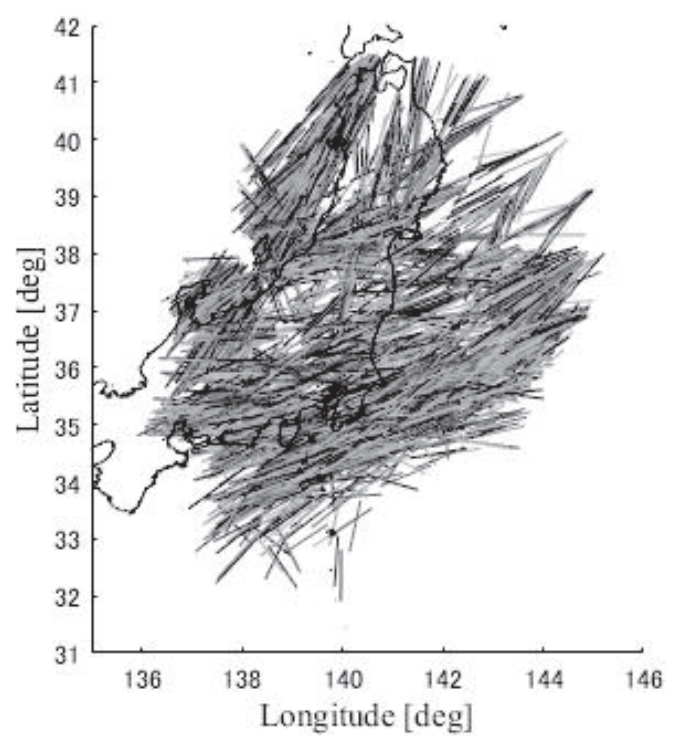

第 1 図 抽出した軌道

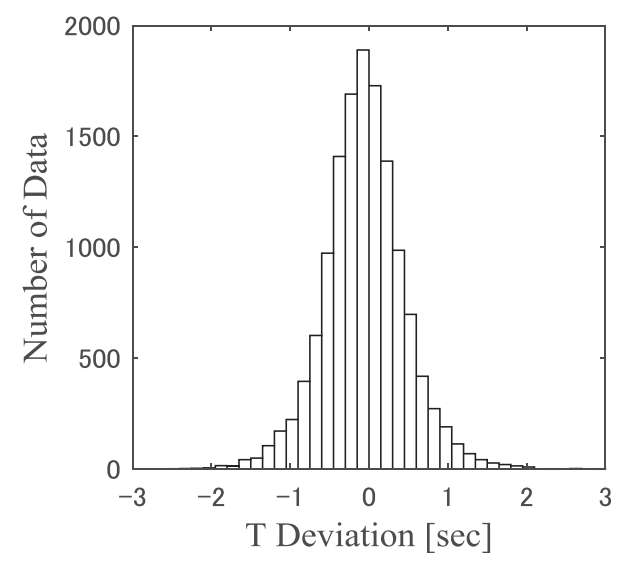

第 2 図 飛行時間の予測誤差の分布

分類後のデータ集合をクラスタという。ここでは, クラスタ リングの基準となる特徵パラメータに，飛行速度や気象状 況を表すパラメータを用いることにより, 分類後のクラスタ によって類似する気象状況で類似する飛行速度をもつ飛行 デー夕集合を模擬する。ここでは特徵パラメータに $10 \mathrm{~km}$ の距離を飛行する間の対地速度, 飛行方向の風速, 横風の 風速の絶対值，気温の平均值を用いる。

気象などの確率的な影響により生じる各飛行パラメータ の分布から各種の統計量を精度よく抽出するためには, ク ラスタリング後のクラスタ内の特徵パラメータが極端な外 れ值を含まない正規分布に近い分布を形成することが望ま しい. そこで混合正規分布の密度推定によるクラスタリン グを用いる．この手法では，まず飛行デー夕集合を特徵パラ メー夕を基底とする多次元空間における複数の多次元正規 分布の重ね合わせとみなし, 構成要素となる各正規分布の 確率密度関数を EM（反復期待值最大化）アルゴリズム ${ }^{12)}$ により推定する。そして, 式 (4) に示す，あるデータ $Y$ が 観測されたときの正規分布 $G_{i}$ の生起確率 $P\left(G_{i} \mid Y\right)$ をデー 夕 $Y$ の正規分布 $G_{i}$ への所属度とみなし, 各データを所属 


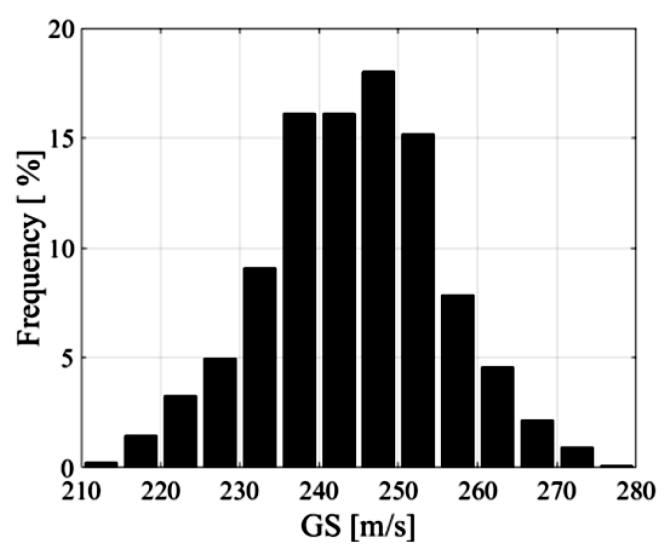

(a) 対地速度の平均值

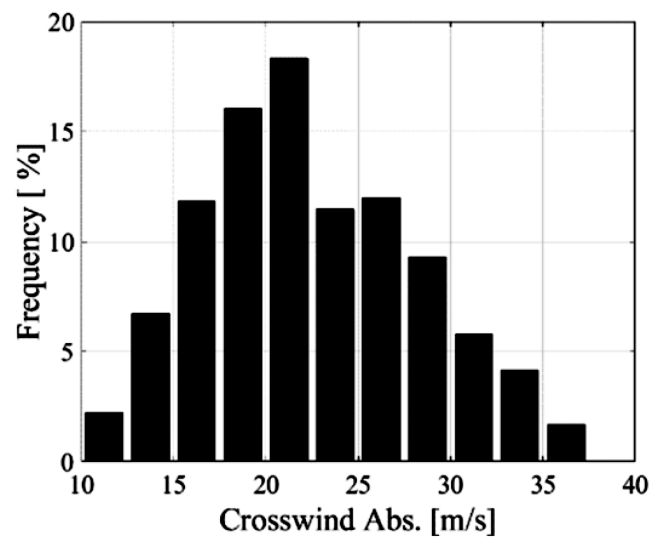

(c) 横風の風速の平均值の絶対値

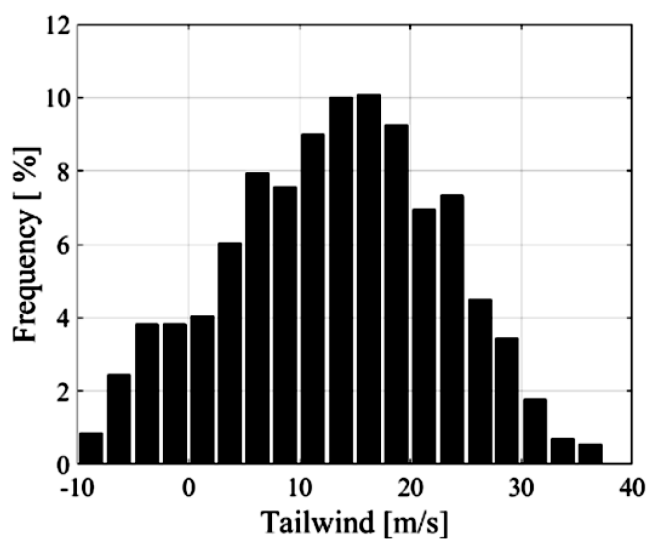

(b) 飛行方向の風速の平均値

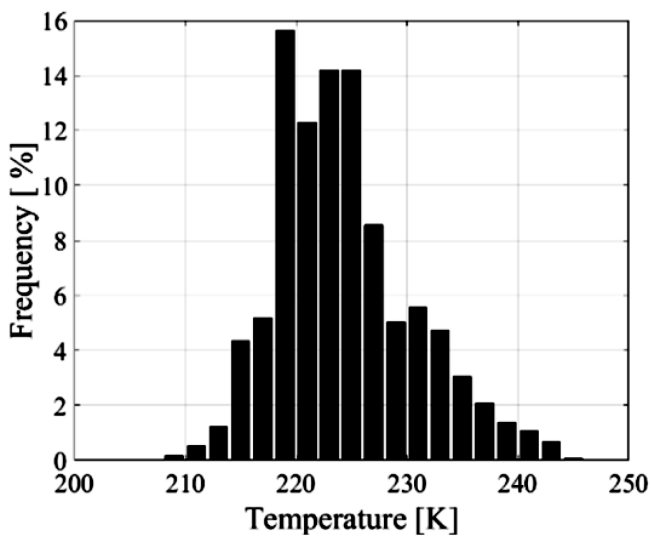

(d) 気温の平均值

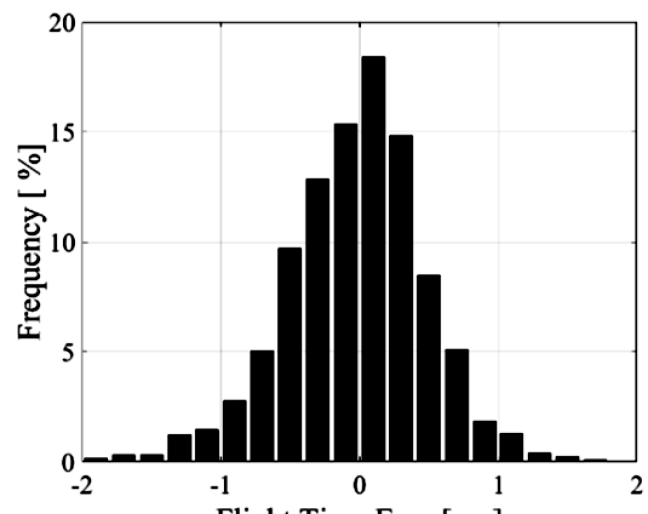

Flight Time Error[sec]

(e) 飛行時間誤差

第 3 図 あるクラスタ内の特徵パラメータの分布

する正規分布に確率的に割り当てることができる13).

$$
P\left(G_{i} \mid Y\right)=\frac{P\left(Y \mid G_{i}\right) P\left(G_{i}\right)}{\sum_{j=1}^{M} P\left(Y \mid G_{j}\right) P\left(G_{j}\right)}
$$

この手法により模擬した類似する飛行状況における飛行デー 夕集合は，特徴パラメータの分布が概ね正規分布に従い，極 端な外れ值をもたない. なお, 次章以降の解析ではクラス 夕内の飛行時間誤差の標準偏差を算出するため, そのデー 夕数が 50 を下回るクラス夕は使用しないこととした．初期 クラスタ数を 250 とした結果，157個のクラスタを得た。こ の例として, ある一つのクラスタ内の特徴パラメータ（対地
速度 $V_{G S}$, 飛行方向の風速 $W_{H}$, 横風の風速の絶対值 $\left|W_{C}\right|$ および気温 Temp の平均值）と飛行時間の予測誤差の分布 を第 3 図に示す。それぞれ極端な外れ值をもたず，山型の 分布となっていることがわかる. また, 各クラスタ内の各 特徵パラメー夕の平均值と飛行時間の予測誤差の標準偏差 の関係を第 4 図に示す。飛行時間の予測誤差の標準偏差と, 対地速度 $V_{G S}$, 飛行方向の風速 $W_{H}$, 横風の風速の絶対值 $\left|W_{C}\right|$ および気温 Tempの平均值との相関係数は，それぞれ $R=-0.85(p<0.01), R=-0.83(p<0.01), R=0.36$ $(p<0.01), R=-0.34(p<0.01)$ であり, いずれのパラ メー夕も飛行時間の予測誤差の標準偏差と有意な相関をも 


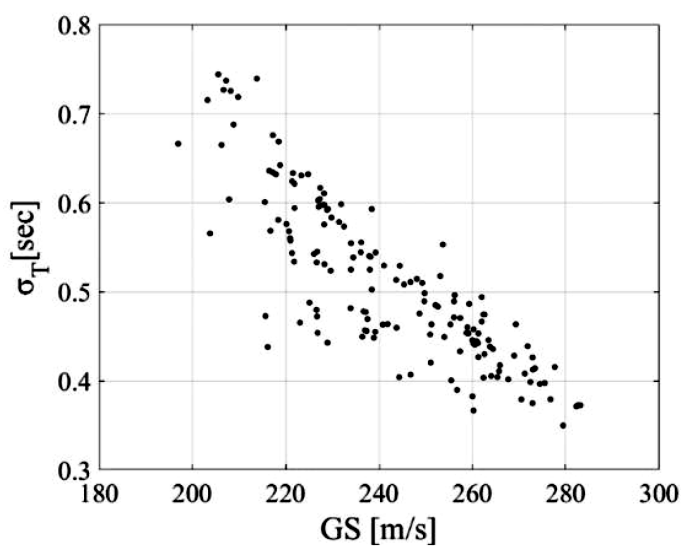

(a) 対地速度

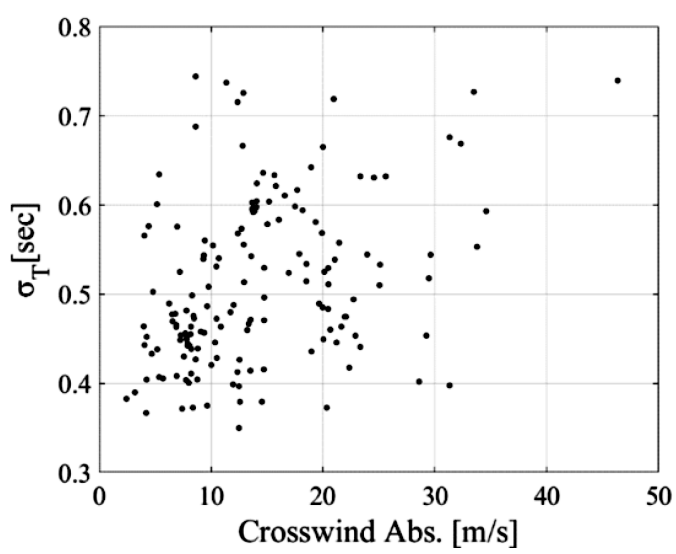

(c) 横風の風速の絶対値

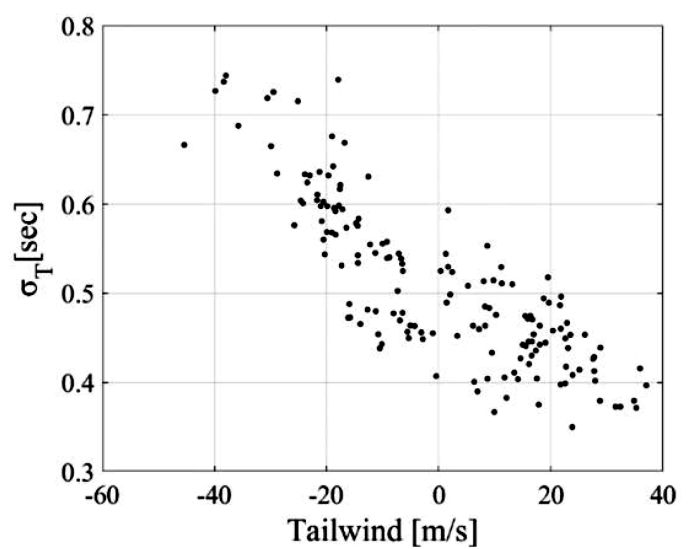

(b) 飛行方向の風速

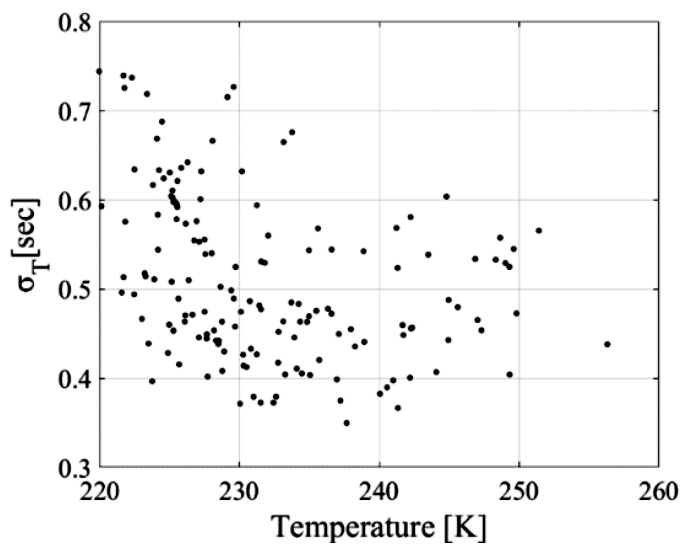

(d) 気温

第 4 図 各特徵パラメータと飛行時間の予測誤差の標準偏差の関係

つことが明らかとなった。

\section{3. 飛行時間の予測誤差の伝搬モデル}

3.1 飛行時間の予測誤差の伝搬モデルの導出 まず，航 空機を質点としてみなした単純な力学モデルに基づく飛行 時間の予測誤差の伝搬モデルについて述べる. 航空機を質 点としてみなした単純な力学モデルにおいて, 飛行時間 $T$ と真対気速度 $V_{T A S}$ および風速 $W_{H}$, 飛行距離 $D$ の関係は 式 (5)のようになる.ただし, 真対気速度 $V_{T A S}$ と風速 $W_{H}$ はどちらも真航路方向成分を考える. 飛行距離 $D$ を一定と すると, 飛行時間 $T$ の予測誤差 $\Delta T$ の誤差要因になり得 るのは, 真対気速度 $V_{T A S}$ および風速 $W_{H}$ の誤差 $\Delta V_{T A S}$, $\Delta W_{H}$ のみであり，この関係は式 (6) のように表せる. 式 (5) と式 (6) から飛行時間の予測誤差 $\Delta T$ は, $\Delta V_{T A S}$ と $\Delta W_{H}$ の関数として式 (7) のように表せ, それらを $V_{T A S}$ と $W_{H}$ に対して微小とみなして線形化すると式 (8) を得る. さらに本論文では単純化のため $V_{T A S}$ と $W_{H}$ が無相関であ ることを仮定すると, 分散の定義式から飛行時間の予測誤 差 $\Delta T$ の標準偏差 $\sigma_{T}$ を式 $(9)$ のように得る. 式 (9) は, 飛 行時間の予測誤差のばらつきが誤差要因のばらつきから発 生する関係を表し，誤差伝搬モデルと呼ばれる。この誤差 伝搬モデルは，一定距離を飛行するときの飛行時間の予測 誤差の標準偏差は対地速度の 2 乗に反比例し, その係数は
真対気速度の誤差分散と風速の誤差分散によって決まるこ とを示している。

$$
\begin{aligned}
& T=\frac{D}{V_{T A S}+W_{H}} \\
& T+\Delta T=\frac{D}{V_{T A S}+\Delta V_{T A S}+W_{H}+\Delta W_{H}} \\
& \Delta T\left(\Delta V_{T A S}, \Delta W_{H}\right) \\
& =\frac{-\left(\Delta V_{T A S}+\Delta W_{H}\right) D}{\left(V_{T A S}+W_{H}\right)\left(V_{T A S}+\Delta V_{T A S}+W_{H}+\Delta W_{H}\right)} \\
& \Delta T\left(\Delta V_{T A S}, \Delta W_{H}\right)=-\frac{D}{\left(V_{T A S}+W_{H}\right)^{2}} \Delta V_{T A S} \\
& -\frac{D}{\left(V_{T A S}+W_{H}\right)^{2}} \Delta W_{H} \\
& \sigma_{T, \text { Model }}=\sqrt{E\left[(\Delta T)^{2}\right]}=\frac{\sqrt{\sigma_{V_{T A S}}{ }^{2}+\sigma_{W_{H}}^{2}}}{V_{G S^{2}}} D
\end{aligned}
$$

3.2 実測值を用いた誤差伝搬モデルの予測精度評価 飛 行時間の予測誤差の伝搬モデル（式 (9)）の出力 $\sigma_{T, \text { Model }}$ と, 実運航データの観測值から得た飛行時間の予測誤差の標 準偏差 $\sigma_{T, \text { Real }}$ を比較することで, 誤差伝搬モデルの予測性 能を評価する，比較評価には $10 \mathrm{~km}$ を飛行したときの飛行 


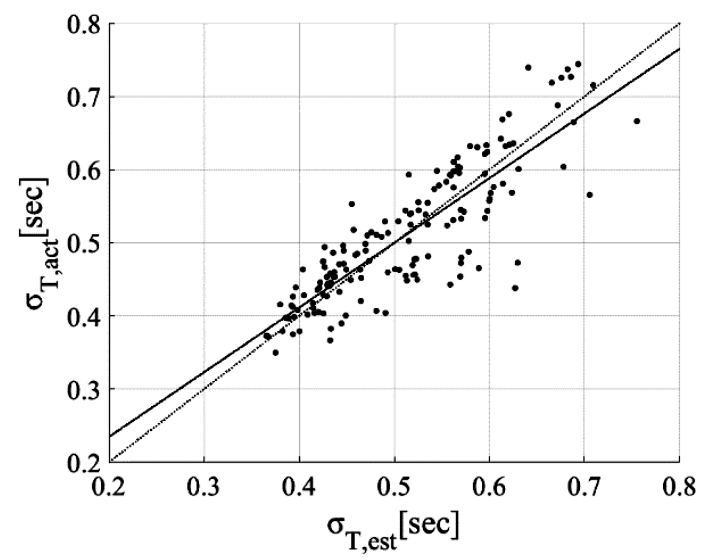

第 5 図予測誤差の標準偏差の散布図と回帰直線（一律の $\sigma_{V_{T A S}}{ }^{2}$, $\sigma_{W_{H}}{ }^{2}$ を入力とした場合)

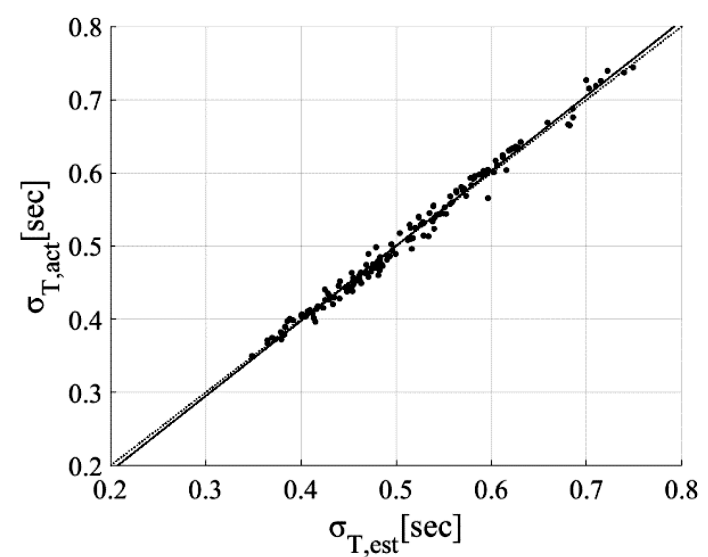

第 6 図 予測誤差の標準偏差の散布図と回帰直線（飛行と気象の状況 ごとの $\sigma_{V_{T A S}}{ }^{2}, \sigma_{W_{H}}{ }^{2}$ を入力とした場合）

時間の予測誤差の標準偏差を用いた。ここで予測モデルの入 力パラメータである誤差要因の誤差分散 $\left(\sigma_{V_{T A S}}{ }^{2}\right.$ と ${\sigma_{W_{H}}}^{2})$ は，13604の飛行デー夕の真大気速度および飛行方向の風 速の誤差分布の分散を算出し，これを実測值としてモデル の入力に用いた。 それぞれの值は， $\sigma_{V_{T A S}}{ }^{2}=0.60\left[\mathrm{~m}^{2} / \mathrm{s}^{2}\right]$ と $\sigma_{W_{H}}{ }^{2}=2.87\left[\mathrm{~m}^{2} / \mathrm{s}^{2}\right]$ となった。第 5 図に予測モデルの 出力 $\sigma_{T, \text { est }}$ と, 実運航デー夕から求めた飛行時間の予測誤 差の標準偏差 $\sigma_{T, \text { act }}$ との散布図と回帰直線を示す.このと き，予測性能を表す予測值と目標值の相関係数 $R$ と RMSE は, $R=0.854(p<0.01), \mathrm{RMSE}=0.049[\mathrm{~s} / 10 \mathrm{~km}]$ と なった。

ここで，入力パラメータである誤差要因の誤差分散に飛行 と気象状況ごとの值を用いる場合について考える。これは, モデルへの入力值である $\sigma_{V_{T A S}}{ }^{2}$ と $\sigma_{W_{H}}{ }^{2}$ にクラスタごとに 算出した值を用いることに相当する.このときの誤差伝搬 モデルの予測精度を第 5 図と同様に第 6 図に示す。このと きの予測值と目標值の相関係数 $R$ と RMSE は, $R=0.99$ $(p<0.01), \mathrm{RMSE}=0.0099[\mathrm{~s} / 10 \mathrm{~km}]$ となった. この結
果は，飛行時間の予測誤差の標準偏差を飛行と気象の状況 によるクラスタリングにより非常に高い精度で予測できる ことを示している.

以上の通り, 従来の研究で示されていた飛行と気象の状 況によらない予測（第 4 図に示す結果に相当する）と比較 して, 飛行と気象の状況ごとの予測（第 5 図に示す結果に相 当する）がより高い精度を達成することが明らかとなった.

\section{4. ま と め}

本研究では，飛行時間の不確かさを事前に予測し管理す ることで，より効率的な運航が期待できることに着目し，そ の予測の可能性を評価した，飛行時間の不確かさを飛行状 況ごとに解析すべく，混合正規分布の密度推定によるクラ スタリングを用いて飛行状況ごとのデータ集合を作成した. そして力学モデルに基づいた飛行時間誤差の誤差伝搬モデ ルを構築し, 飛行と気象の状況ごとに変動する誤差要因を モデルに反映することにより高精度な予測が可能になるこ とを明らかにした。今後の実用化に向けては，様々なパラ メータの影響により飛行時間の不確かさが発生するメカニ ズム，および各要因の重要性を明らかにすることが課題と なる。

\section{参 考 文 献}

1) Boeing: Current Market Outlook 2013-2032, 2013.

2) 将来の航空交通システムに関する研究会：将来の航空交通システ ムに関する長期ビジョン，国土交通省，2010.

3）矢田士郎：四次元航法とそれに対応する管制に関する一考察，第 5 回電子航法研究所研究発表会, 2005 .

4) Paielli, R. A. and Erzberger, H.: Conflict Probability for Free Flight, J. Guid. Control Dynam., 20, 3 (1997), pp. 588-596.

5) Irvine, R.: A Geometrical Approach to Conflict Probability Estimation, Air Traffic Control Quarterly, 10, 2 (2002), pp. $85-113$

6) Paielli, R. A.: Empirical Test of Conflict Probability Estimation, USA/Europe Air Traffic Management Research and Development Seminar, Orlando, 1998.

7) Robert, E. and De Smedt, D.: Comparison of Operational Wind Forecasts with Recorded Flight Data, 10th USA/Europe Air Traffic Management Research and Development Seminar, Chicago, June 10-13, 2013.

8) Takeichi, N., Tachibana, M., Abumi, Y. and Bayasgalan, E.: Waypoint Optimization for Accurate Pseudo-RTA in Descent Trajectory, IEEE/AIAA 34th Digital Avionics Systems Conference, Prague, September 13-17, 2015.

9）元谷章博，武市 昇：四次元航法における飛行時間のばらつきの モデル化，日本航空宇宙学会論文集，65 (2017), pp. 130-134.

10) Senoguchi, A. and Koga, T.: Analysis of Downlink Aircraft Parameters Monitored by SSR Mode S in ENRI, 28th Digital Avionics Systems Conference, Orlando, Florida, October $25-29,2009$.

11）気象庁データ オリジナルデー夕 数值予報 GPV—生存圈デー タベース, http://database.rish.kyoto-u.ac.jp/arch/jmadata/ data/gpv/original/ (2016/12/3 アクセス)

12) Redner, R. A. and Walker, H. F.: Mixture Densities, Maximum Likelihood and the EM Algorithm, SIAM Rev., 26, 2 (1984), pp. 195-239.

13) 宮本定明：クラスター分析入門，第 1 版，森北出版，東京， 1993, pp. 53-56. 